\title{
The Essential Oil Compositions of Origanum majorana L. Cultivated in Konya and Collected from Mersin-Turkey
}

\author{
Yavuz Bağci"*, Yüksel Kan², Süleyman Doğu3, Sadiye Ayşe Çelik² \\ ${ }^{1}$ Department of Biology, Faculty of Science and Art, Selcuk University, Konya, TURKEY. \\ ${ }^{2}$ Selcuk University, Agriculture Faculty, Department of Medicinal Plants, 42049, Konya, TURKEY. \\ ${ }^{3}$ Department of Biology, Faculty of Education Meram, Necmettin Erbakan University, TR 42090 Konya, TURKEY.
}

\begin{abstract}
Purpose: In this study, essential oil (EO) compositions of the dried and fresh aerial parts of Origanum majorana cultivated in the research field and collected from $f$ from Mersin was investigated. Material and Methods: EO was distilled by using Clevenger type apparatus for $3 \mathrm{~h}$ and the chemical compositions were detected in GC-MS. While, the oil yields of the the collected marjoram was determined to be $2,5 \mathrm{ml}$ both in dried and fresh aerial parts, the yields of the cultivated plants for fresh and dried parts were $3.6 \mathrm{ml}$ and $5 \mathrm{ml}$, respectively. The cultivation of the plant had positive effects on the EO yield. Drying of the material also increased the oil yield in the cultivated marjoram. Results: While there were 42 and 35 of EO components were observed in the fresh and dried parts of the collected marjoram, respectively; in the cultivated plants there were 30 and 40 components detected. Besides EO yields, in this research the differences with respect to composition and components were determined between the cultivated and collected plants. On the other hand, in this study, it was determined that the EO compositions varied with respect to be fresh or dry of the plant parts. It was observed that carvacrol and linalool were the major EO contents. Conclusion: The aim of the study to compare of differences between the EO compounds and compositions varied according to be the plant fresh or dry and collected or cultivated.
\end{abstract}

Key words: Oregano, Origanum majorana, Essential Oil Composition, Carvacrol, Linalool, Oil Yield.

\section{INTRODUCTION}

Lamiaceae/Labiatae comprise of ca. 7200 species and 236 genera. The family is represented by 45 genera, 546 species and 730 taxa in Turkey. The members of the Lamiaceae are common mainly in the mountainous areas of the Mediterranean parts of Turkey. The herbs of Lamiaceae family possess two types of glandular trichomes on the surface of their leaves, termed peltate and capitate glands. ${ }^{1-10}$ Recent investigations showed ${ }^{4}$ that most (if not all) of the essential oil (EO) was on the surface of leaves in peltate glandular trichomes (peltate glands). Many species of family are aromatic and often used as herb species, folk medicines and fragrences. This property stems from this family's glandular hairs secreting rich oil and ether. More taxa of Lamiaceae generally used as hemostatic plants and for its tonic property.

The genus Origanum (Labiatae), known as "oregano" in English, is an annual, perennial and shrubby herb that is native to the Mediterranean, Euro-Siberian and Irano-Siberian regions. A total 38 Origanum species are recognized in the World. Most of the Origanum species, over $75 \%$, are concentrated in the East Mediterranean sub region. Of them, 16 species are considered as endemic for the flora of Turkey. ${ }^{5}$ Origanum species grow abundantly on stony slopes
DOI: $10.5530 /$ ijper.51.3s.68 Correspondence: Yavuz Bağcı, Department of Biology, Faculty of Science and Art, Selcuk University, Konya, TURKEY.

Phone no: +905334652169 E-mail: ybagci66@gmail.com

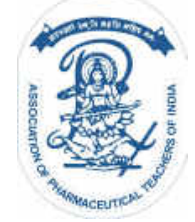

www.ijper.org 
and in rocky mountain areas at a wide range of altitudes $(0-4000 \mathrm{~m})$. Due to the variability in chemical and aroma characteristics, Origanum plants belongs to different species and ecotypes (biotypes). ${ }^{8}$

Sweet marjoram (Origanum majorana L. Syn. Majorana hortensis), a member of the Lamiaceae family, is a herbaceous, perennial plant native to Cyprus and the Eastern Mediterranean. It can be grown in Northern European areas with mulching materials ${ }^{6}$ In tropical countries fresh plants can be affected by mould diseases. It is of great economic and industrial importance. ${ }^{10}$ Commercial Origanum majorana $\mathrm{L}$. oil is used as a spice and condiment. The fresh or dried highly aromatic leaves and flowering tops of marjoram (Origanum majorana L.) are widely used to flavor many foods. In Turkish cuisine, oregano is mostly used for flavoring of meat, especially for mutton and lamb. In barbecue and kebab restaurants, it can be usually found on Table, together with paprika, salt and pepper.

The volatile aromatic compounds are employed in the food industry as flavouring in foods and beverages. The oil is used in perfumery for its spicy herbaceous notes ${ }^{9}$ and as fungicides or insecticides in pharmaceutical and industrial products. ${ }^{4}$

Marjoram contains $0.5-3.5 \%$ of essential oil in dry herb. ${ }^{11}$ The composition of the oil and its content in the herb also changes under the influence of fertilizing with different types of nitrogenous fertilizers and liming. ${ }^{3-6}$ Origanum majorana has strong antioxidant activity, mainly because of its high content of phenolic acids and flavonoids, which is useful in health supplements and food preservation. Traditionally, the plant has been used as a folk remedy against asthma, indigestion, headache and rheumatism. Furthermore, Origanum majorana (marjoram) are used as blood anti-coagulator in Iranian folk medicine.

\section{MATERIAL AND METHODS \\ MATERIALS}

Plant materials were collected in 2015 from Mersin and Selcuk University, Field Crops Department, Medical Plant Garden. A voucher specimen has been deposited at the KNYA herbarium.

\section{METHODS}

Aerial parts (dried and fresh branch, leaf and herb) of the Origanum majorana were subjected to hydrodistillation for $3 \mathrm{~h}$ using Clevenger type apparatus to produce EO. The essential oils (EOs) were stored at $-20^{\circ} \mathrm{C}$ until analysed. The compositions of Origanum majorana L. (OME), EOs were identified by The GC-MS analyses.

\section{RESULTS AND DISCUSSION}

As a result of the studies done, the volatile oil components of wet and dry specimens of Origanum majorana plant cultivated and from nature were compared (Table 1, Figure 1-3). Table 1 revelaed that there were significant $(p<0.01)$ differences between the the aerial parts of

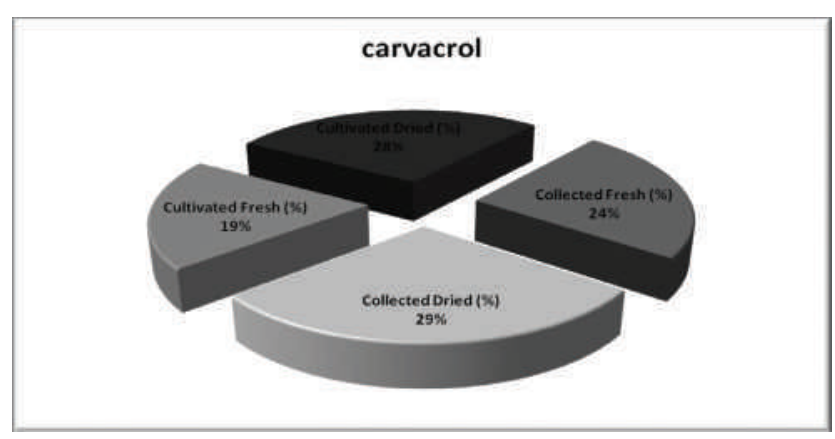

Figure 1: Carvacrol contents of collected and cultivated dried and fresh aerial parts of Origanum majorana.

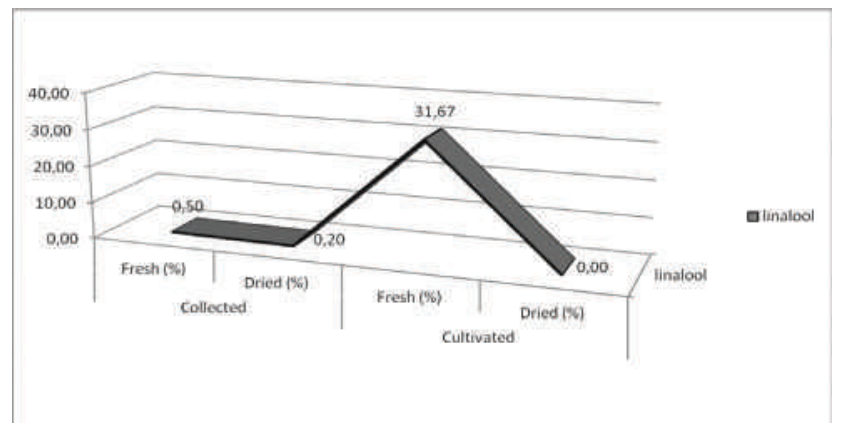

Figure 2: Linalool contents of collected and cultivated dried and fresh aerial parts of Origanum majorana.

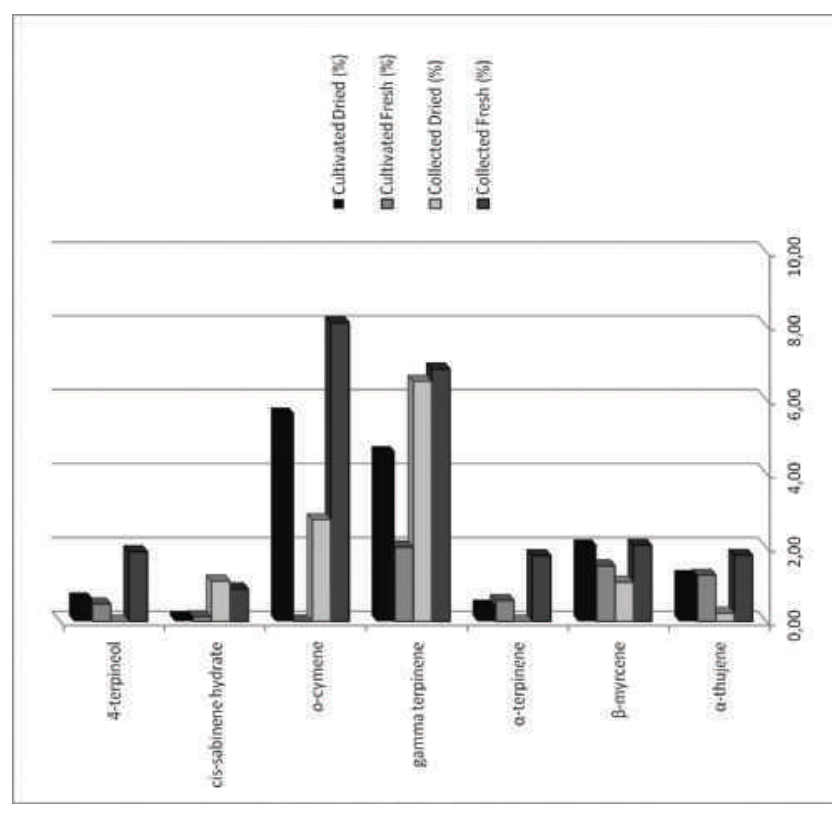

Figure 3: The major essential oil compositions of collected and cultivated dried and fresh aerial parts of Origanum majorana. 
Table 1: The comparison of the essential oil compositions of the collected and cultivated Origanum majorana

\begin{tabular}{|c|c|c|c|c|c|c|c|c|c|}
\hline \multirow[b]{2}{*}{ RI } & \multirow[b]{2}{*}{ Compounds } & \multirow{2}{*}{$\begin{array}{l}\text { Collected } \\
\text { Fresh (\%) }\end{array}$} & \multirow{2}{*}{$\begin{array}{l}\text { Cultivated } \\
\text { Fresh (\%) }\end{array}$} & \multirow{2}{*}{$\begin{array}{l}\text { Collected } \\
\text { Dried (\%) }\end{array}$} & \multirow{2}{*}{$\begin{array}{l}\text { Cultivated } \\
\text { Dried (\%) }\end{array}$} & \multicolumn{2}{|c|}{ Collected } & \multicolumn{2}{|c|}{ Cultivated } \\
\hline & & & & & & $\begin{array}{l}\text { Fresh } \\
(\%)\end{array}$ & $\begin{array}{c}\text { Dried } \\
(\%)\end{array}$ & $\begin{array}{c}\text { Fresh } \\
(\%)\end{array}$ & $\begin{array}{c}\text { Dried } \\
(\%)\end{array}$ \\
\hline 1009 & methyl 2-methylbutanoate & 0,13 & 0,00 & 0,00 & 0,07 & 0,12 & 0,00 & 0,00 & 0,05 \\
\hline 1022 & a-pinene & 0,98 & 0,41 & 0,12 & 0,70 & 0,98 & 0,12 & 0,41 & 0,70 \\
\hline 1026 & a-thujene & 1,79 & 1,24 & 0,21 & 1,24 & 1,79 & 0,21 & 1,26 & 1,24 \\
\hline 1067 & camphene & 0,33 & 0,07 & 0,04 & 0,14 & 0,33 & 0,04 & 0,07 & 0,14 \\
\hline 1111 & $\beta$-pinene & 0,23 & 0,12 & 0,09 & 0,18 & 0,25 & 0,09 & 0,12 & 0,18 \\
\hline 1123 & sabinene & 0,07 & 0,14 & 0,00 & 0,04 & 0,07 & 0,00 & 0,14 & 0,04 \\
\hline 1149 & delta-3-carene & 0,12 & 0,08 & 0,00 & 0,10 & 0,12 & 0,00 & 0,08 & 0,10 \\
\hline 1163 & $\beta$-myrcene & 2,04 & 1,51 & 1,07 & 2,07 & 2,06 & 1,07 & 1,51 & 2,07 \\
\hline 1166 & a-phellandrene & 0,29 & 0,18 & 0,09 & 0,08 & 0,29 & 0,07 & 0,17 & 0,08 \\
\hline 1179 & a-terpinene & 1,79 & 0,57 & 0,00 & 0,44 & 1,79 & 0,00 & 0,57 & 0,44 \\
\hline 1180 & delta-2-carene & 0,00 & 0,00 & 0,98 & 0,00 & 0,00 & 0,55 & 0,00 & 0,00 \\
\hline 1197 & limonene & 0,33 & 0,13 & 0,16 & 0,20 & 0,33 & 0,16 & 0,13 & 0,20 \\
\hline 1203 & $\beta$-phellandrene & 0,65 & 0,00 & 0,00 & 0,33 & 0,65 & 0,00 & 0,00 & 0,33 \\
\hline 1204 & 1,8-cineole & 0,00 & 0,02 & 0,00 & 0,00 & 0,00 & 0,00 & 0,01 & 0,00 \\
\hline 1205 & sabinene & 0,00 & 0,10 & 0,21 & 0,00 & 0,00 & 0,21 & 0,10 & 0,00 \\
\hline 1211 & trans-2-hexenal & 0,00 & 0,00 & 0,00 & 0,04 & 0,00 & 0,00 & 0,00 & 0,04 \\
\hline 1224 & gamma terpinene & 6,84 & 2,02 & 6,51 & 4,60 & 6,84 & 6,51 & 2,02 & 4,60 \\
\hline 1226 & $\beta$-ocimene & 0,15 & 0,00 & 0,07 & 0,08 & 0,15 & 0,07 & 0,00 & 0,08 \\
\hline 1227 & 1,3,6-octatriene,3,7-dimethyl & 0,00 & 0,00 & 0,00 & 0,07 & 0,00 & 0,00 & 0,00 & 0,07 \\
\hline 1237 & $p$-cymene & 0,00 & 2,45 & 0,00 & 0,00 & 0,00 & 0,00 & 2,45 & 0,00 \\
\hline 1238 & o-cymene & 8,09 & 0,00 & 2,76 & 5,64 & 8,08 & 2,76 & 0,00 & 5,64 \\
\hline 1243 & a-terpinolene & 0,15 & 0,06 & 0,04 & 0,16 & 0,15 & 0,04 & 0,05 & 0,14 \\
\hline 1292 & 3-hexen-1-ol & 0,00 & 0,00 & 0,00 & 0,02 & 0,00 & 0,00 & 0,00 & 0,02 \\
\hline 1294 & 3-octanol & 0,00 & 0,00 & 0,00 & 0,02 & 0,00 & 0,00 & 0,00 & 0,02 \\
\hline 1439 & 2-allytoluene & 0,00 & 0,00 & 0,00 & 0,02 & 0,00 & 0,00 & 0,00 & 0,01 \\
\hline 1440 & cis-linalool oxide & 0,00 & 0,03 & 0,00 & 0,00 & 0,00 & 0,00 & 0,02 & 0,00 \\
\hline 1444 & 1-octen-3-ol & 0,24 & 0,09 & 0,11 & 0,17 & 0,24 & 0,09 & 0,07 & 0,15 \\
\hline 1460 & cis-sabinene hydrate & 0,86 & 0,11 & 1,10 & 0,13 & 0,88 & 1,11 & 0,13 & 0,13 \\
\hline 1523 & camphor & 0,03 & 0,00 & 0,00 & 0,00 & 0,03 & 0,00 & 0,00 & 0,00 \\
\hline 1539 & linalool & 0,51 & 31,68 & 0,21 & 0,00 & 0,51 & 0,21 & 31,68 & 0,00 \\
\hline 1546 & trans sabinene hydrate & 0,26 & 0,57 & 0,23 & 0,59 & 0,26 & 0,23 & 0,57 & 0,59 \\
\hline 1562 & $\begin{array}{l}\text { 2-cyclo hexen-1-ol, } 1 \text { methyl- } \\
\text { 4-(1-methylethyl)-trans }\end{array}$ & 0,07 & 0,00 & 0,00 & 0,00 & 0,07 & 0,00 & 0,00 & 0,00 \\
\hline 1565 & $\begin{array}{l}\text { trans 2-cyclohexen-1-ol, } 1 \\
\text { methyl-4-(1-methyl ethyl) }\end{array}$ & 0,00 & 0,00 & 0,00 & 0,03 & 0,00 & 0,00 & 0,00 & 0,03 \\
\hline 1604 & 4-terpineol & 1,89 & 0,48 & 0,00 & 0,64 & 1,89 & 0,00 & 0,48 & 0,64 \\
\hline 1605 & trans caryophyllene & 0,00 & 0,43 & 1,04 & 0,06 & 0,00 & 1,04 & 0,43 & 0,06 \\
\hline 1616 & aromadendrene & 0,17 & 0,00 & 0,00 & 0,00 & 0,17 & 0,00 & 0,00 & 0,00 \\
\hline 1617 & cis dihydro carvone & 0,00 & 0,05 & 0,06 & 0,03 & 0,00 & 0,00 & 0,05 & 0,03 \\
\hline 1628 & 1-terpineol & 0,04 & 0,00 & 0,00 & 0,00 & 0,04 & 0,00 & 0,00 & 0,00 \\
\hline 1638 & trans dihydro carvone & 0,00 & 0,00 & 0,03 & 0,00 & 0,00 & 0,05 & 0,00 & 0,00 \\
\hline
\end{tabular}




\begin{tabular}{|c|c|c|c|c|c|c|c|c|c|}
\hline 1639 & dihydrocarvone & 0,05 & 0,00 & 0,00 & 0,00 & 0,07 & 0,00 & 0,00 & 0,00 \\
\hline 1682 & a-humulene & 0,08 & 0,00 & 0,10 & 0,00 & 0,08 & 0,10 & 0,00 & 0,00 \\
\hline 1690 & geranial & 0,02 & 0,00 & 0,00 & 0,00 & 0,02 & 0,00 & 0,00 & 0,00 \\
\hline 1701 & a-terpineol & 0,65 & 0,24 & 0,32 & 0,14 & 0,65 & 0,32 & 0,24 & 0,14 \\
\hline 1707 & ledene & 0,04 & 0,00 & 0,00 & 0,00 & 0,04 & 0,00 & 0,00 & 0,00 \\
\hline 1710 & linalyl-propionate & 0,00 & 0,00 & 0,00 & 0,11 & 0,00 & 0,00 & 0,00 & 0,11 \\
\hline 1719 & borneol & 0,65 & 0,03 & 0,06 & 0,29 & 0,67 & 0,06 & 0,03 & 0,28 \\
\hline 1724 & $\beta$-copaene & 0,00 & 0,00 & 0,14 & 0,00 & 0,00 & 0,14 & 0,00 & 0,00 \\
\hline 1749 & bicyclogermacrene & 0,02 & 0,00 & 0,06 & 0,00 & 0,02 & 0,06 & 0,00 & 0,00 \\
\hline 1751 & carvone & 0,09 & 0,25 & 0,00 & 0,09 & 0,07 & $0,00^{\circ}$ & 0,25 & 0,07 \\
\hline 1795 & methyl solicylate & 0,00 & 0,00 & 0,02 & 0,00 & 0,00 & 0,02 & 0,00 & 0,00 \\
\hline 1854 & cuminol & 0,04 & 0,00 & 0,00 & 0,00 & 0,04 & 0,00 & 0,00 & 0,02 \\
\hline 1855 & para-cymen-8-ol & 0,00 & 0,00 & 0,02 & 0,00 & 0,00 & 0,02 & 0,00 & 0,00 \\
\hline 1882 & carvacryl acetate & 0,00 & 0,00 & 0,02 & 0,00 & 0,00 & 0,02 & 0,00 & 0,00 \\
\hline 1891 & thymol acetate & 0,00 & 0,00 & 0,00 & 0,02 & 0,00 & 0,00 & 0,00 & 0,01 \\
\hline 1941 & $\begin{array}{l}\text { 4-hydroxy-3-(1-methylethyl) } \\
\text { benzaldehyde }\end{array}$ & 0,10 & 0,00 & 0,00 & 0,00 & 0,04 & 0,00 & 0,00 & 0,00 \\
\hline 2009 & caryophyllene oxide & 0,21 & 0,06 & 0,09 & 0,33 & 0,21 & 0,09 & 0,06 & 0,33 \\
\hline 2038 & farnesol & 0,00 & 0,00 & 0,02 & 0,00 & 0,00 & 0,01 & 0,00 & 0,00 \\
\hline 2051 & trans-nerolidol & 0,00 & 0,00 & 0,00 & 0,01 & 0,00 & 0,00 & 0,00 & 0,02 \\
\hline 2089 & elemol & 0,00 & 0,00 & 0,00 & 0,00 & 0,00 & 0,03 & 0,00 & 0,00 \\
\hline 2141 & spathulenol & 0,08 & 0,05 & 0,07 & 0,07 & 0,10 & 0,09 & 0,07 & 0,09 \\
\hline 2187 & thymol & 0,57 & 0,38 & 0,51 & 0,68 & 0,57 & 0,51 & 0,38 & 0,69 \\
\hline 2223 & carvacrol & 69,50 & 56,40 & 83,47 & 80,34 & 69,50 & 83,47 & 56,40 & 80,34 \\
\hline 2292 & durenol & 0,02 & 0,00 & 0,00 & 0,00 & 0,02 & 0,00 & 0,00 & 0,00 \\
\hline 2438 & $\begin{array}{l}\text { Di 9-methyl-9phenyl-9.10- } \\
\text { dihydrophenenthrene }\end{array}$ & 0,04 & 0,00 & 0,00 & 0,00 & 0,04 & 0,00 & 0,00 & 0,00 \\
\hline 2439 & $\begin{array}{l}\text { S-indacene-1.7- } \\
\text { dione,2,3,5,6-tetrahydro- } \\
\text { 3,3,4,5,5,8-hexamethyl }\end{array}$ & 0,00 & 0,00 & 0,07 & 0,00 & 0,00 & 0,07 & 0,00 & 0,00 \\
\hline 2860 & cuminol & 0,00 & 0,00 & 0,00 & 0,33 & 0,00 & 0,00 & 0,00 & 0,35 \\
\hline
\end{tabular}

dried and fresh Origanum majorana (collected and cultivated) with respect to their $\mathrm{EO}$ compositions. While, the oil yields of the the collected marjoram was determined to be 2,5 $\mathrm{ml}$ both in dried and fresh aerial parts, the yields of the cultivated plants for fresh and dried parts were $3.6 \mathrm{ml}$ and $5 \mathrm{ml}$, respectively. It can be easily seen that cultivation had positive effects on the EO yield. Drying of the material also increased the oil yield in the cultivated marjoram. The cultivation of marjoram will provide more profit (bring to profit) than collected plants. Because, in smaller area or fields, production can be controlled easily.

EO composition may vary considerably between aromatic plant species and varieties, and within the same variety from different enviromental areas Besides EO yields, in this research the differences with respect to composition and components were determined between the cultivated and collected plants. On the other hand, in this study, it was determined that the $\mathrm{EO}$ compositions varied with respect to be fresh or dry of the plant parts. While there were 42 and 35 of EO components were observed in the fresh and dried parts of the collected marjoram, respectively; in the cultivated plants there were 30 and 40 components detected.

The results clearly showed that the highest EO content was carvacrol both in collected and cultivated fresh $(69.49 \%$ and $56.39 \%)$ and dried $(83.46 \%$ and $80.33 \%)$ aerial parts. It can be stated (said) that drying of the plant material had positive effect on the rate of carvacrol. On the other hand, linalool was the second dominating 


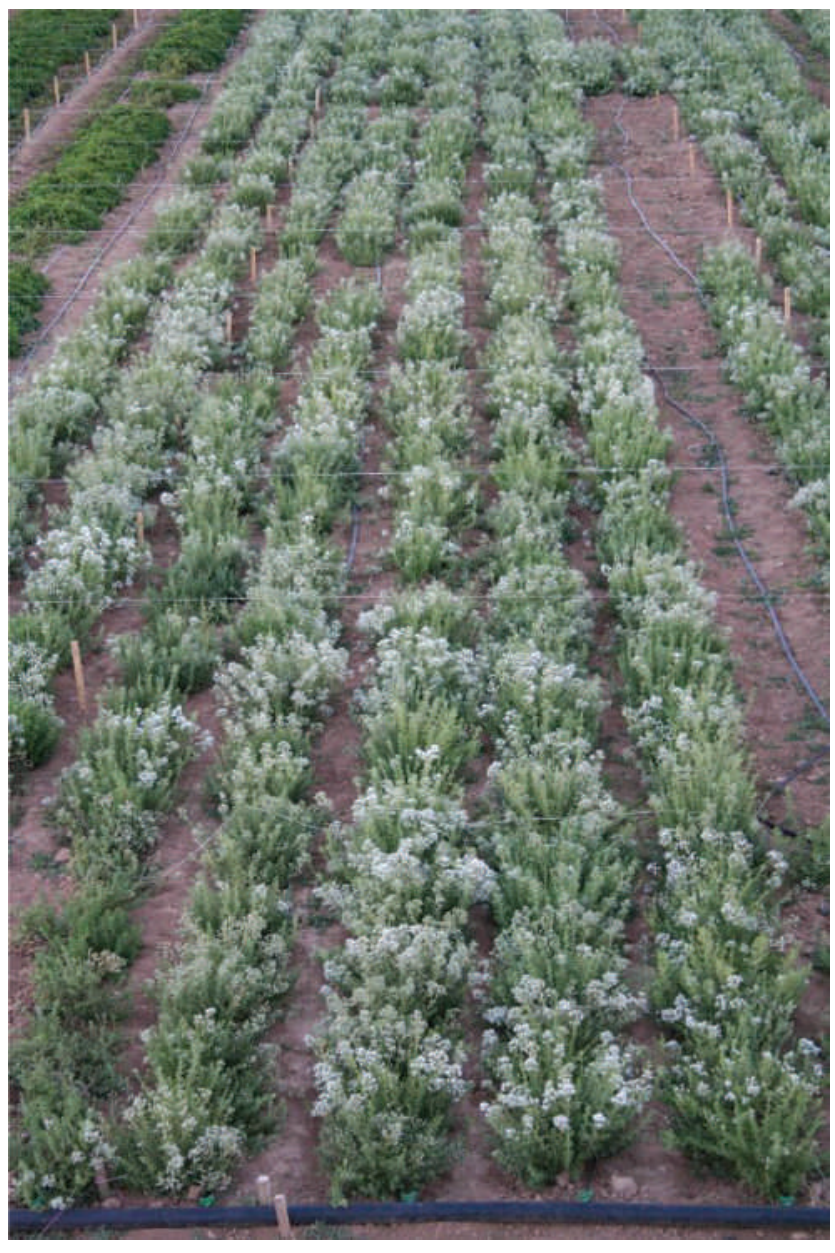

Photo 1: Origanum majorana general view.

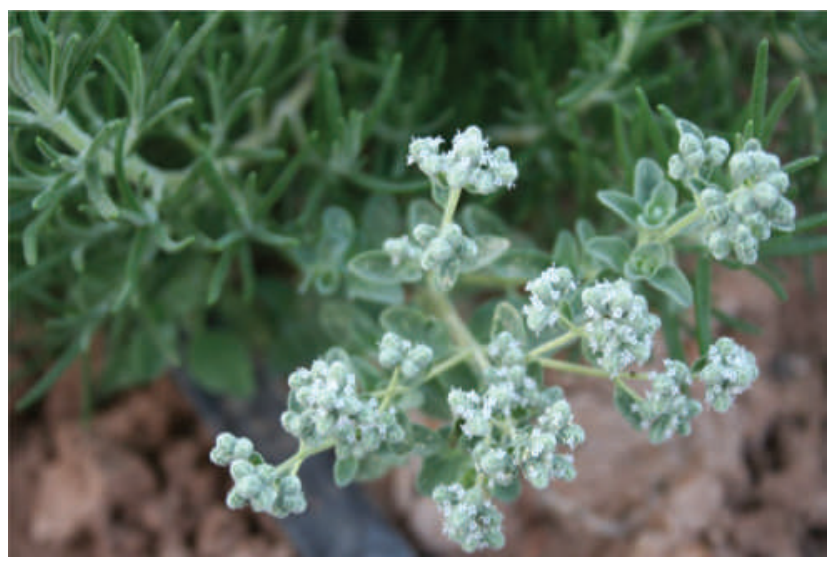

Photo 2: Origanum majorana flowers.

content and although it was detected in significantly in cultivated fresh parts $(31.67 \%)$, there were not observed in cultivated fresh part. On the contrast of carvacrol, drying of the material had negative effect on the linalool content. Carvacrol and linalool contents were also presented in Figures 1 and 2

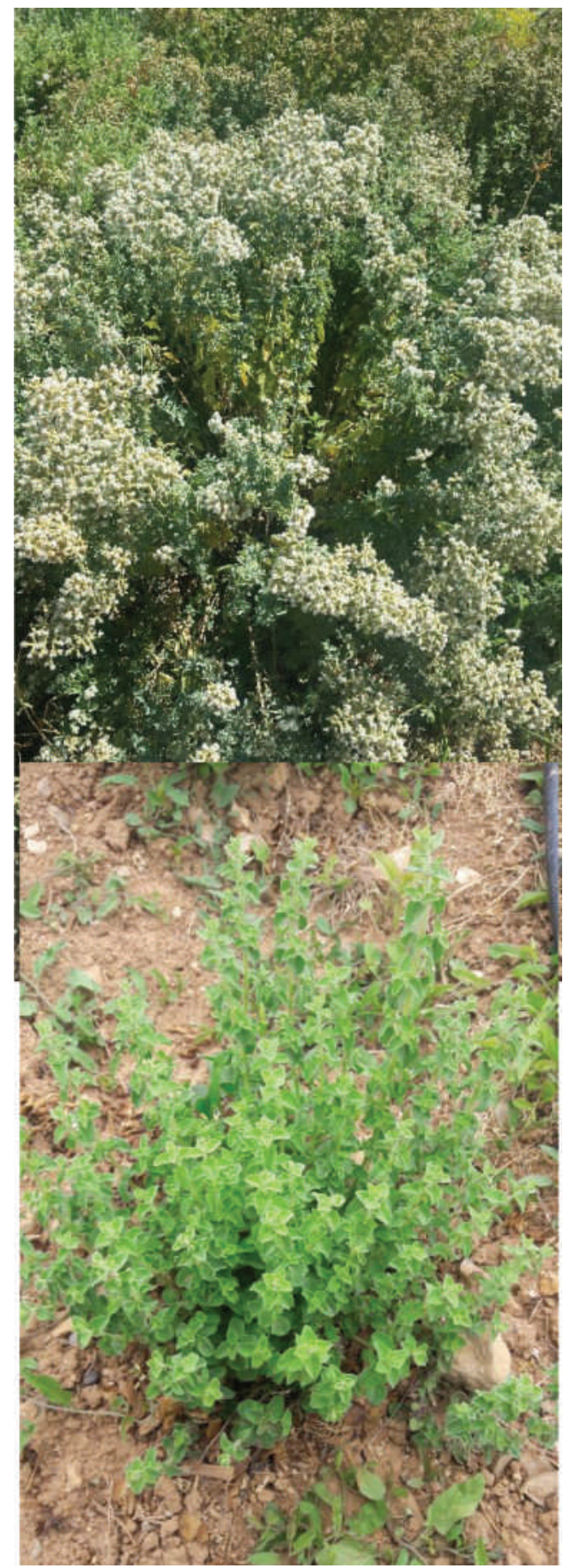

Photo 3: Origanum majorana herb. 
o-cymene and gamma-terpinene were observed at the rate of $2.75 \%$ and $6.50 \%$ respectively, while the contents were detected at the rate of $8.08 \%$ and $6.83 \%$ in the collected fresh part. Besides collected plant, in the cultivated dried part, the contents were detected at the rate of $5.63 \%$ and $4.59 \%$, respectively.

The objective of the study to compare of differences between the EO compounds and compositions varied according to be the plant fresh or dry and collected or cultivated.

\section{CONCLUSION}

The results of this study demonstrate that the aim of the study to compare of differences between the EO compounds and compositions varied according to be the plant fresh or dry and collected or cultivated. It was observed that carvacrol and linalool were the major EO contents.

\section{ACKNOWLEDGEMENT}

The authors are thankful for the technical helping to the University of Selcuk.

\section{CONFLICT OF INTEREST}

Authors declare that there is no conflict of interest.

\section{ABBREVIATION USED}

EO: Essential oil; GC-MS: Gas Chromatography-Mass Spectrophotometry; h: hours; ml: milliliter; OME: Origanum majorana L. Essential oil; RI: Retention Indices.

\section{REFERENCES}

1. Burt S. Essential oils: their antibacterial properties and potential applications in foods - a review. International Journal of Food Microbiology. 2004;94(3):223-53.

2. Deans SG, Svoboda KP.The antimicrobial properties of marjoram (Origanim majorana L.) volatile oil. Flavour and Fragrance Journal. 1990;5(3):187-90.

3. Dzida K, Jarosz Z. Acta Agrophysica. 2006;7(3):561.

4. Soliman FM, Yousif MF, Zaghloul SS, Okba MM. Seasonal Variation in the Essential Oil Composition of Origanum majorana L. Cultivated in Egypt. Essential ois and Aromatic plants. 2009;64(9-10):611-4

5. Güner A, Özhatay N, Ekim T \& Başer KHC. 2000. Flora of Turkey and The East Aegean Islands Supplement 2). Edinburgh Üniv. Pres. Vol. 11, Edinburgh.

6. Halva S. Studies on production techniques of some herb plants. I. Effect on Agryl P 17 mulching on herb yield and volatile oils of basil (Ocimum basilicum L.) and marjoram (Origanum majorana L.). J. Agric. Sci. Finland. 1987;59:31-6.

7. Kozłowski J, Nowak A. Herba Polonica. 1983;29(1):13.

8. Snogerup S. Evolutionary and plant geographical aspects of Chasmophytic communities. In Davis, P. H., Harper, P. C. \& Hedge, I. C. (Eds.), Plant life of South-West Asia 1917;(pp, 157-170). Edinburgh: The Botanical Society.

9. Vera, Chane-Ming. Chemical composition of the essential oil of marjoram (Origanum majorana L.) from Reunion Island. Food Chemistry. 1999;66(2):143-5.

10. Werker E. Function of essential oil-secreting glandular hairs in aromatic plans of Lamiacea-a review. Flavour and fragrance journal. 1993;8(5):249-55.

11. Tabanca M, Ozek T, Baser KHC. Comparison of the Essential Oils of Origanum majorana L. and Origanum $\times$ majoricum Cambess. J Essent Oil Res 2004;16(3):248-52.

\section{SUMMARY}

- The genus Origanum L. is a member of Lamiaceae family. Origanum majorana is a perennial herb aerial parts of Origanum majorana L. oil is used as a spice and condiment. The fresh or dried highly aromatic leaves and flowering tops of marjoram (Origanum majorana L.) are widely used to flavour many foods. In Turkish cuisine, oregano is mostly used for flavoring of meat, especially for mutton and lamb. In barbecue and kebab restaurants, it can be usually found on table, together with paprika, salt and pepper. As a result of the studies done, the volatile oil components of wet and dry specimens of Origanum majorana plant cultivated and from nature were compared. The aim of the study to compare of differences between the EO compounds and compositions varied according to be the plant fresh or dry and collected or cultivated.

- The results clearly showed that the highest $\mathrm{EO}$ content was carvacrol both in collected and cultivated fresh $(69.49 \%$ and $56.39 \%)$ and dried $(83.46 \%$ and $80.33 \%)$ aerial parts. Alsa, in the collected at nature dried part o-cymene and gamma-terpinene were observed at the rate of $2.75 \%$ and $6.50 \%$ respectively, while the contents were detected at the rate of $8.08 \%$ and $6.83 \%$ in the collected fresh part. Besides collected plant, in the cultivated dried part, the contents were detected at the rate of $5.63 \%$ and $4.59 \%$, respectively. 


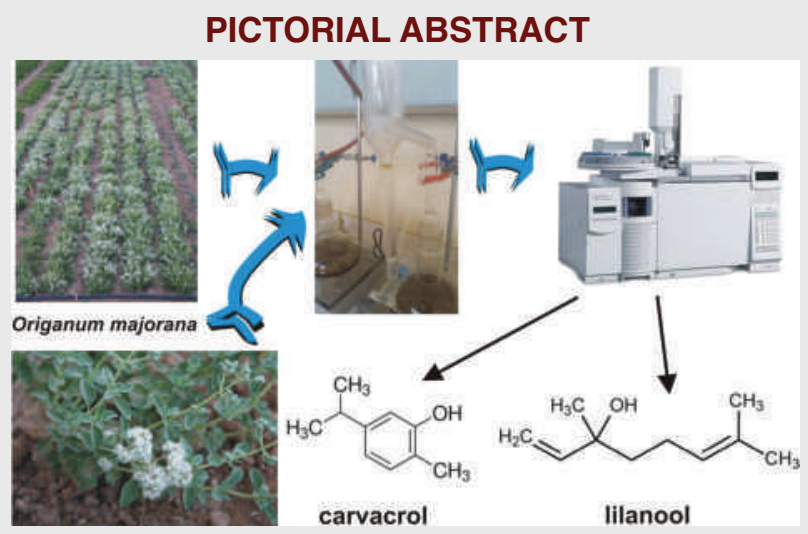

\section{ABOUT AUTHORS}

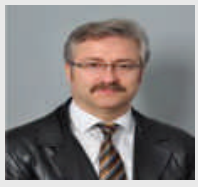

Prof. Dr. Yavuz BAGCl: He has completed his Ph. D. from Dept. of Biology, Selcuk University. His major research area and publications are Plant taxanomy, plant morphology, plant anatomy, palinology, ethnobotany, phytochemistry. He has published more than 50 research papers in international journals. He is presently working as Professor Dr. of Pharmaceutical Botany, Selcuk University Konya.

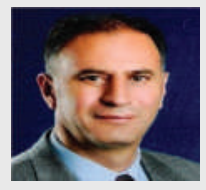

Prof. Dr. YükseL KAN: He is a researcher with 30 years experience working with medicinal and aromatic plants. Is presently working as Professor Department of Medicinal Plants, Faculty of Agriculture Selçuk University Konya, Turkey. He has published more than 80 research papers in international journals.

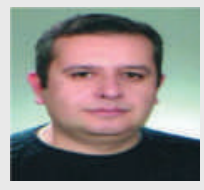

Ass. Prof. Dr. Süleyman Dogu: He is presently working as Assistant Professor, Department of Biology, Necmettin Erbakan University Konya, Turkey. His major research area and publications are Plant taxanomy, plant morphology, plant anatomy, palinology, ethnobotany, phytochemistry. He has published more than 40 research papers in international journals.

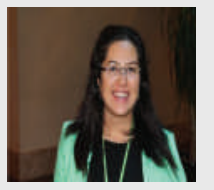

Ph. D. Expert S. Ayșe ÇELiK: She is working as Ph. D Expert, Department of Medicinal Plants since 2009, Faculty of Agriculture Selçuk University Konya, Turkey. Her research areas are medicinal and aromatic plants cultivation and their harvesting, seconder methabolites in medicinal plants, essential oil analysis, GC-MS analysis.

Cite this article: Bagci $Y$, Kan Y, Dogu S, C elik SA. The Essential Oil Compositions of Origanum majorana L. Cultivated in Konya and Collected from Mersin-Turkey. Indian J of Pharmaceutical Education and Research. 2017;51(3)Suppl:S463-69. 